\title{
Sex- and age-specific associations between cardiometabolic risk and white matter brain age in the UK Biobank cohort
}

\author{
Sivaniya Subramaniapillai*a,b, Sana Suric ${ }^{\mathrm{c}, \mathrm{d}}$, Claudia Barth ${ }^{\mathrm{e}, \mathrm{f}}$, Ivan I. Maximove,g,h, Irene \\ Voldsbekk ${ }^{\mathrm{e}, \mathrm{g}}$, Dennis van der Meer ${ }^{\mathrm{e}, \mathrm{i}}$, Tiril P. Gurholt ${ }^{\mathrm{e}}$, Dani Beck ${ }^{\mathrm{e}, \mathrm{f}, \mathrm{g}}$, Bogdan Draganski ${ }^{\mathrm{a}, \mathrm{j}}$, \\ Ole A. Andreassen ${ }^{\mathrm{e}, \mathrm{k}}$, Klaus P. Ebmeier ${ }^{\mathrm{c}}$, Lars T. Westlye ${ }^{\mathrm{e}, \mathrm{g}, \mathrm{k}}$, Ann-Marie G. de Lange*a,c,g \\ ${ }^{a}$ LREN, Centre for Research in Neurosciences, Department of Clinical Neurosciences, Lausanne University \\ Hospital (CHUV) and University of Lausanne, Lausanne, Switzerland \\ ${ }^{b}$ Dept. of Psychology, Faculty of Science, McGill University, Montreal, Canada \\ ${ }^{c}$ Dept. of Psychiatry, University of Oxford, Oxford, UK \\ ${ }^{d}$ Wellcome Centre for Integrative Neuroimaging, University of Oxford, Oxford, UK \\ ${ }^{e}$ Norwegian Centre for Mental Disorders Research (NORMENT), Division of Mental Health and Addiction, \\ Oslo University Hospital and University of Oslo, Oslo, Norway \\ ${ }^{f}$ Dept. of Psychiatric Research, Diakonhjemmet Hospital, Oslo, Norway \\ ${ }^{g}$ Dept. of Psychology, University of Oslo, Oslo, Norway \\ ${ }^{h}$ Dept. of Health and Functioning, Western Norway University of Applied Sciences, Bergen, Norway \\ ${ }^{i}$ School of Mental Health and Neuroscience, Faculty of Health Medicine and Life Sciences, Maastricht \\ University, The Netherlands \\ ${ }^{j}$ Dept. of Neurology, Max Planck Institute for Human Cognitive and Brain Sciences, Leipzig, Germany \\ ${ }^{k} K G$ Jebsen Centre for Neurodevelopmental Disorders, University of Oslo, Oslo, Norway
}

Abstract: Cardiometabolic risk factors (CMRs) are associated with accelerated brain aging and increased risk for sex-dimorphic illnesses such as Alzheimer's Disease (AD). Yet, it is unknown how CMRs interact with sex and apolipoprotein E- $\epsilon 4$ (APOE4), a known genetic risk factor for $\mathrm{AD}$, to influence brain age across different life stages. Using age prediction based on multi-shell diffusion-weighted imaging data in 21,308 UK Biobank participants, we investigated whether associations between white matter Brain Age Gap (BAG) and body mass index (BMI), waist-to-hip ratio (WHR), body fat percentage (BF\%), and APOE4 status varied i) between males and females, ii) according to age at menopause in females, and iii) across different age groups in males and females. We report sex differences in associations between BAG and all three CMRs, with stronger positive associations among males compared to females. Higher BAG (older brain age relative to chronological age) was associated with greater BMI, WHR, and BF\% in males, whereas in females, higher BAG was associated with greater WHR, but not $\mathrm{BMI}$ and $\mathrm{BF} \%$. These divergent associations were most prominent within the oldest group of females (66-81yrs), where higher BF\% was linked to lower BAG (younger brain age relative to chronological age). Earlier menopause transition was associated with higher BAG, but no interactions were found with CMRs. APOE4 status was not significantly associated with BAG, and no significant interactions with CMRs were found. In conclusion, the findings point to sex- and age-specific associations between body fat composition and brain age. Incorporating sex as a factor of interest in studies addressing cardiometabolic risk may promote sex-specific precision medicine, consequently improving health care for both males and females.

Keywords: Brain age; Sex differences; $A P O E$ genetic risk; Cardiometabolic health; Menopause

*Author correspondence: sivaniya.subramaniapillai@mail.mcgill.ca; ann-marie.de-lange@chuv.ch 


\section{Introduction}

Cardiometabolic risk factors (CMRs) such as obesity are associated with adverse health outcomes including accelerated brain aging [1] and increased risk for Alzheimer's disease (AD) $[2,3]$. The impact of both CMRs and genetic risk for AD, such as apolipoprotein E- $\epsilon 4$ (APOE4), are known to differ between males and females [4, 5, 6, 7, 8, 9]. Yet, it is unknown whether these risk factors interact in sex-specific ways to influence brain health across different age periods or endocrine life stages. While males experience greater incidence and prevalence of cardiometabolic disease in early midlife, the greatest risk of cardiometabolic disease in females is observed up to ten years later, coinciding with the menopausal transition $[10,11]$. Post menopause, female $\mathrm{APOE}_{4}$ carriers are also at greater AD risk than their male counterparts $[8,9]$, but it is unknown whether a reduction in neuroprotective ovarian hormones, combined with an elevated cardiometabolic and genetic risk profile, may accelerate brain aging and subsequent $\mathrm{AD}$ risk in females compared to males. Investigating how CMRs interact with $A P O E$ genotype to influence the brain at different life stages, whether age- or menopause-related, may thus clarify sex-specific risk profiles for accelerated brain aging and illuminate critical periods for preventive interventions.

Poor cardiometabolic health is associated with changes in brain microvasculature, which may be reflected in magnetic resonance imaging (MRI)-derived indices of white matter (WM) microstructure [12]. CMRs such as adiposity, hypertension, smoking, and diabetes have been associated with lower fractional anisotropy [13, 14, 15], lower myelin and iron content [16], and greater WM hyperintensity (WMH) burden $[4,17,18,19,20,21]$ in healthy older adults. Although females usually have higher volumes of WMH than males [20, 22, 23, 24, 25], extensive literature indicates that males with CMRs (adiposity, hypertension, diabetes, atherosclerosis) are more likely to develop WMH compared to females with similar levels of risk $[4,7,26,27,28]$. Hence, cardiometabolic health may influence WM microstructure differ-

ently in males and females, and risk profiles may also vary with age. Despite the consensus that high blood pressure and cholesterol levels are associated with accelerated brain aging and elevated dementia risk [29, 30, 31], the role of body fat is inconclusive [32, 33]. While mixed findings may be a result of selection or survivor bias [34, 35, 36, 37], or variation in 
body fat indices used across studies (e.g., body mass index (BMI) versus waist-to-hip ratio (WHR) or body fat percentage (BF\%) [38, 39, 40, 41], they could also reflect a variable role of body composition throughout the lifespan. For example, one study found that BMI had a positive association with dementia risk when measured $>20$ years before dementia diagnosis, and a negative association when measured $<10$ years before dementia diagnosis [42]. Low BMI at later life stages may indicate indicate frailty, sarcopenia (muscle loss), or preclinical dementia [43, 44, 45, 46]. Hence, while high BMI in mid-adulthood may largely reflect obesity, higher BMI in senescence may reflect overall physical fitness or lack of degenerative diseases. Furthermore, body fat may act as a source of estrogen in post-menopausal females [47], potentially protecting against WM decline [48]. However, only a few studies have tried to disentangle the role of body fat composition in endocrine versus chronological aging $[49,50]$. Since risk profiles for adverse brain health may vary by sex across certain life stages, it is relevant to investigate specific age windows at which CMRs may have sex- and genotype-specific effects on the brain.

One strategy for detecting atypical brain aging, particularly if it does not involve visible pathognomonic hallmarks of degenerative brain disease, is to use machine learning to predict an individual's age based on neuroimaging-derived measures [51, 52, 53]. Brain Age Gap (BAG) provides a measure of deviation from expected age trajectories, and has been used to identify differences in patients with neurological and psychiatric disorders relative to healthy controls $[54,53,55,56,57,58]$, as well as predicting future dementia risk [59] and prognosis [60, 61, 62, 63]. While individual variation in BAG reflects a combination of genetic and environmental factors $[53,64,65]$, clinical studies indicate that an older 'brain age' relative to what is expected for an individual's chronological age (i.e., positive BAG) may in part reflect accelerated neural aging processes $[53,54,55,56,57,66,67]$. Positive BAG values have also been associated with negative outcomes in population-based studies, including cardiovascular risk, cognitive impairments, and dementia risk [59, 61, 62, 63, 68, 69, 70, 71]. Previous studies have shown accurate age prediction based on diffusion-weighted imaging measures $[72,73,74,75]$, as well as associations between WM BAG and CMRs [1, 76]. However, these previous studies did not assess sex-specific effects, or whether CMRs interact with APOE 
genotype to influence WM BAG during certain life phases.

In this study, we examined the associations between WM BAG and key CMRs, including BMI, WHR, and BF\% [77, 78, 79], and APOE4 status in males $(\mathrm{N}=10,605)$ and females $(\mathrm{N}=10,703)$. We further assessed whether these risk factors had salient effects in middle age (44-55yrs) and different stages of older adulthood (56-65yrs and 66-82yrs) [80, 81, 82]. Participants' brain ages were computed using a prediction model based on WM measures derived from three diffusion imaging modes: diffusion tensor imaging (DTI) [83], diffusional kurtosis imaging (DKI) [84], and WM tract integrity (WMTI) [85]. While DTI is commonly used to estimate WM indices that are highly sensitive to age [73, 86, 87, 88], biophysical diffusion models such as WMTI [85], which is derived from DKI [84], may more accurately capture WM tissue structure complexity [84, 89], thus providing greater biological specificity [90]. Given previous work indicating structural and functional sex differences in the human

brain [91, 92, 93, 94], the diffusion metrics were used as input features to three separate prediction models; 1) mixed-sex, 2) female only, and 3) male only, in order to improve the accuracy of the sex-specific analyses $[53,95,96]$. We used linear regression models to assess whether associations between BAG and BMI, WHR, BF\%, and APOE genotype varied i) between males and females, ii) according to age at menopause in females, and iii) across different age groups in males and females.

\section{Methods and Materials}

\subsection{Sample characteristics}

The initial sample was drawn from the UK Biobank cohort (www.ukbiobank.ac.uk), and included 39,232 participants with diffusion-weighted imaging and demographic data. We excluded 3,379 participants with diagnosed brain disorders based on ICD10 (chapter V and VI, field F; mental and behavioural disorders, including F00 - F03 for Alzheimer's disease and dementia, and F06.7 'Mild cognitive disorder', and field G; diseases of the nervous system, including inflammatory and neurodegenerative diseases (except G55-59; "Nerve, nerve root and plexus disorders"). Diagnostic details are provided in the UK Biobank online resources (http://biobank.ndph.ox.ac.uk/showcase/field.cgi?id=41270), and in the ICD10 
diagnostic manual (https://www.who.int/classifications/icd/icdonlineversions). In addition, 113 participants were excluded based on MRI outliers (see section 2.2), leaving a total of 35,740 participants with diffusion-weighted imaging data that were included in the brain age models. Only participants with complete data on demographic factors, APOE genotype, BMI, WHR, and BF\% from the MRI assessment time point were included in the subsequent analyses, yielding a final sample of 21,308 (male $=10,605$, female $=10,703$ ). Sample demographics are provided in Table 1. Sex of participants refers to binary data on biological sex acquired from the NHS registry at recruitment, but in some cases updated by the participant (see https://biobank.ndph.ox.ac.uk/showcase/field.cgi?id=31).

Table 1: Sample demographics. Mean \pm standard deviation (SD) and ranges for age, body mass index (BMI), waist-to-hip ratio (WHR), and body fat percentage (BF\%), and \% in each group for ethnic background, education, assessment location, and APOE 4 status. GCSE $=$ General Certificate of Secondary Education, $\mathrm{NVQ}=$ National Vocational Qualification. $\mathrm{KW}=$ Kruskal-Wallis, $X^{2}=$ chi-squared test.

\begin{tabular}{|c|c|c|c|c|c|}
\hline Variable & & Male & Female & $P$-value & Test \\
\hline $\mathbf{N}$ & & 10,605 & 10,703 & & \\
\hline \multirow[t]{2}{*}{ Age } & Mean $\pm \mathrm{SD}$ & $64.58 \pm 7.65$ & $63.12 \pm 7.33$ & $<0.001$ & KW \\
\hline & Range [years] & $44.57-81.30$ & $45.48-81.89$ & & \\
\hline \multirow[t]{6}{*}{ Ethnic background } & $\%$ White & 97.33 & 97.39 & $<0.001$ & $X^{2}$ \\
\hline & $\%$ Black & 0.47 & 0.62 & & \\
\hline & $\%$ Mixed & 0.35 & 0.46 & & \\
\hline & $\%$ Asian & 1.31 & 0.63 & & \\
\hline & $\%$ Chinese & 0.20 & 0.30 & & \\
\hline & $\%$ Other & 0.34 & 0.61 & & \\
\hline \multirow[t]{6}{*}{ Education } & $\%$ University/college degree & 50.00 & 47.81 & $<0.001$ & $X^{2}$ \\
\hline & $\%$ A levels or equivalent & 12.08 & 15.00 & & \\
\hline & $\%$ O levels/GCSE or equivalent & 17.06 & 20.41 & & \\
\hline & $\%$ NVQ or equivalent & 11.32 & 6.67 & & \\
\hline & $\%$ Professional qualification & 3.92 & 5.56 & & \\
\hline & $\%$ None of the above & 5.62 & 4.56 & & \\
\hline \multirow[t]{3}{*}{ Assessment location (N) } & Newcastle & 1916 & 1999 & 0.04 & $X^{2}$ \\
\hline & Cheadle & 7280 & 7178 & & \\
\hline & Reading & 1409 & 1526 & & \\
\hline \multirow[t]{2}{*}{$A P O E 4$ status } & $\%$ carrier & 25.48 & 26.65 & 0.05 & $X^{2}$ \\
\hline & $\%$ non-carrier & 74.52 & 73.35 & & \\
\hline \multirow[t]{2}{*}{ BMI } & Mean $\pm \mathrm{SD}$ & $26.72 \pm 3.60$ & $25.65 \pm 4.18$ & $<0.001$ & KW \\
\hline & Range & $16.38-39.95$ & $14.55-39.99$ & & \\
\hline \multirow[t]{2}{*}{ WHR } & Mean $\pm \mathrm{SD}$ & $0.81 \pm 0.07$ & $0.80 \pm 0.06$ & $<0.001$ & KW \\
\hline & Range & $0.53-1.26$ & $0.60-1.16$ & & \\
\hline \multirow[t]{2}{*}{ BF\% } & Mean $\pm \mathrm{SD}$ & $25.12 \pm 5.47$ & $35.57 \pm 6.44$ & $<0.001$ & $\mathrm{KW}$ \\
\hline & Range & $5.20-42.50$ & $7.40-57.5$ & & \\
\hline
\end{tabular}




\subsection{MRI data acquisition and processing}

A detailed overview of the UK Biobank data acquisition and protocols is available in [97] and [98]. Briefly, we processed diffusion-weighted imaging data using an optimized diffusion pipeline as described in detail in [99]. We included metrics derived from DTI [83], DKI [84], and WMTI [85] as input features in the age prediction models, as described in [75]. The metrics for each model are listed in Supplementary Information (SI) section 1. The metrics were extracted based on subject-specific skeletonized images [100], and Johns Hopkins University (JHU) atlases for white matter tracts (with 0 thresholding) [101] were used to provide global mean values and regional measures for 12 tracts used in previous aging and development studies $[75,86,87,88]$; anterior thalamic radiation, corticospinal tract, cingulate gyrus, cingulum hippocampus, forceps major, forceps minor, inferior fronto-occipital fasciculus, inferior longitudinal fasciculus, superior longitudinal fasciculus, uncinate fasciculus, superior longitudinal fasciculus temporal, and corpus callosum. The included diffusion MRI data passed Tract-based spatial statistics (TBSS) post-processing quality control using the YTTRIUM algorithm [102], and were residualized with respect to scanning site using linear models. To remove further outliers, participants with $\mathrm{SD} \pm 4$ on the global mean FA measure were excluded, yielding a final sample of 35,740 participants with MRI data (male = 16,909, female $=18,831)$. To optimize prediction accuracy, the full MRI sample was included in the brain age models (Section 2.3), while the subsequent analyses (Section 2.5 - 2.6) included only participants with complete data on CMRs and APOE genotype ( $\mathrm{N}=21,308$; Table 1$)$.

\subsection{Brain age prediction}

We ran three age prediction models: 1) mixed-sex, 2) female only, and 3) male only, to obtain sex-specific BAG values $[53,95]$ as well as general BAG estimates based on the mixed sample. The prediction models were run using the XGBoost regression algorithm (eXtreme Gradient Boosting; https://github.com/dmlc/xgboost). XGboost includes advanced regularisation to reduce over-fitting, and has shown superior performance in machine learning competitions [103]. Parameters were tuned in a nested cross-validation using 5 inner folds for grid search,

and 10 outer folds for model validation. Feature importance rankings for each model were extracted using gain scores, which are calculated based on each feature's contribution to each 
tree in the model and thus indicate the relative contribution of each feature to the prediction. BAG values were calculated by subtracting chronological age from predicted brain age. The age and BAG distributions for each of the age prediction models are shown in SI Figure 1. To ensure that associations with the variables of interest were not driven by age-dependence in the BAG estimations [104, 105], chronological age was regressed out of the BAG values before they were used in subsequent analyses [106, 107].

\subsection{APOE genotyping}

Participants' APOE genotype was extracted using the UK Biobank version 3 imputed data, which has been rigorously assessed for quality control by the UK Biobank genetics team [108]. The two APOE single-nucleotide polymorphisms - rs7412 and rs429358 [109] were used to estimate $A P O E$ genotype. APOE $\epsilon 4$ status was labelled carrier for $\epsilon 3 / \epsilon 4$ and $\epsilon 4 / \epsilon 4$ combinations, and non-carrier for $\epsilon 2 / \epsilon 2, \epsilon 2 / \epsilon 3$ and $\epsilon 3 / \epsilon 3$ combinations [110]. We removed participants with the homozygous $\epsilon 2 / \epsilon 4$ allele combination due to its ambiguity with $\epsilon 1 / \epsilon 3$ [111, 109]. For more information on the genotyping process please refer to [108].

\subsection{Cardiometabolic risk factors: BMI, WHR and BF\%}

CMRs included BMI $\left(\mathrm{kg} / \mathrm{m}^{2}\right)$, WHR (waist circumference / hip circumference), and BF\% based on body composition by impedance measurement. All assessment procedures are described in detail in the UK Biobank protocol [112]. As compared to BMI, which is a general measure of body adiposity, BF\% distinguishes fat from muscles, while WHR is a more specific measure of abdominal obesity. Participants with BMI $>40$ were excluded (N $=196)$, since these values indicate morbid obesity and risk for serious health complications and comorbidities $[113,114]$. The correlations between BMI, WHR, and BF\% are shown in Figure 1, indicating shared variance corresponding to previous studies $[77,115,116,117,118]$. 

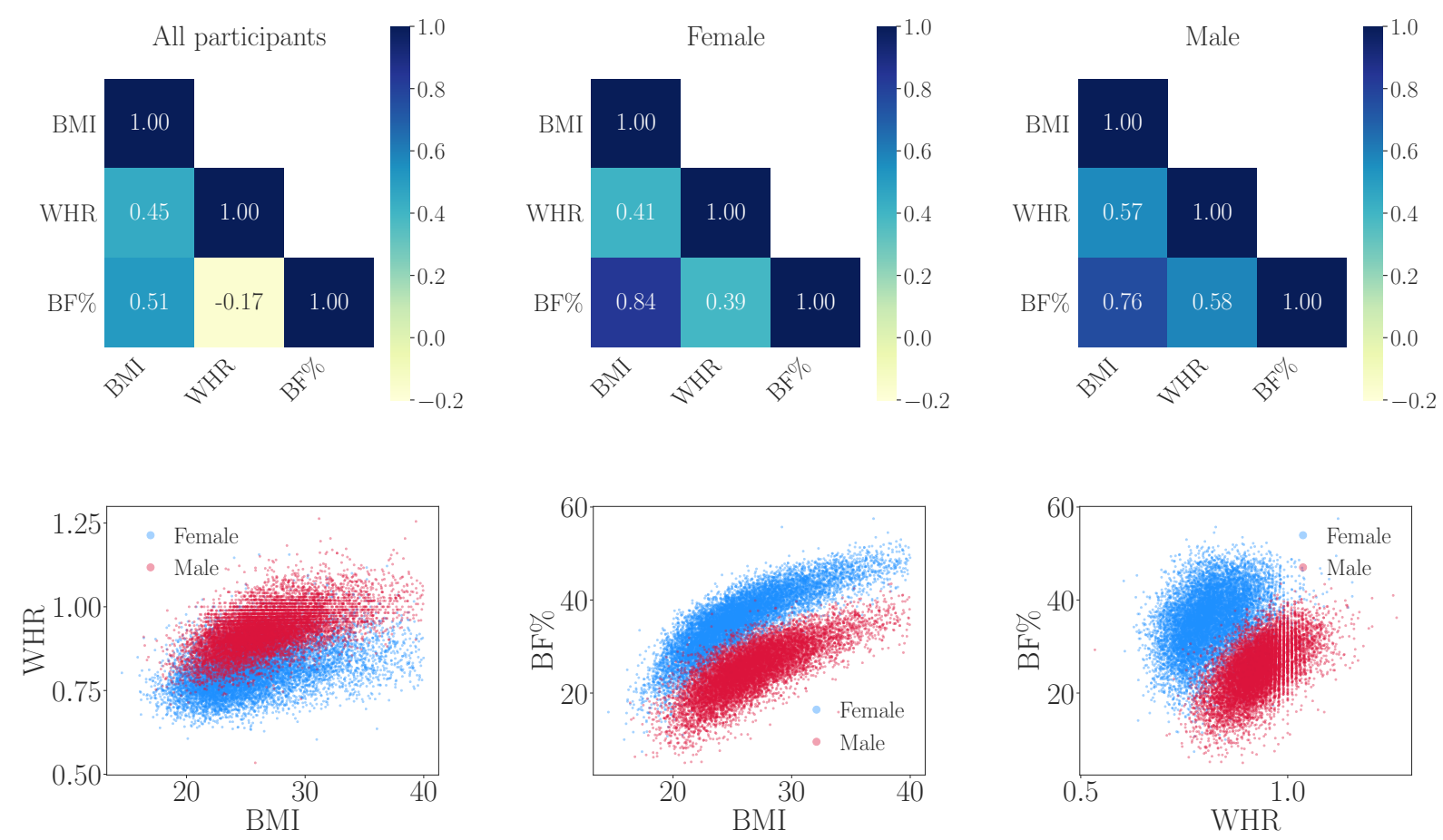

Figure 1: The matrices (top row) show the correlations (Pearson's coefficients) between BMI, WHR, and $\mathrm{BF} \%$ for all participants, as well as females and males separately. The scatter plots (bottom row) show the correlations for all participants with males plotted in red and females in blue.

\subsection{Categorising groups based on i) age at menopause and ii) chronological age}

To investigate whether associations of BAG with CMRs and APOE genotype varied according to age at menopause, we analyzed data from a subset of menopausal females who had complete information on age at menopause $(\mathrm{N}=8,770)$. Based on previous studies binning age at menopause in approximately 5-year group bins [119, 120], we applied similar age at menopause (i.e., Menopause Age Group) categories to our sample using the following bins: 40-45 years, 46-50 years, 51-55 years, and 56-62 years (Table 2). Since the average age of menopause is typically around 51.5 years and perimenopause lasts on average 4 years [121] [122], we excluded females with age at menopause $<40$ years and $>62$ years from our analyses to ensure that results were not driven by outliers. We also excluded participants who had undergone a hysterectomy and/or oophorectomy before natural menopause, as these females often experience premature menopause associated with their surgery and may be at elevated risk of dementia [123]. Distributions for BMI, WHR, and BF\% within each Menopause Age Group are shown in SI Figure 2. 
To investigate whether effects of CMRs and $A P O E$ risk varied across different age groups, we categorised participants' ages (i.e., Age Group) using the following bins: 45-55 years, 5665 years, and 66-82 years (Table 2). The bins were selected to take the full cohort age range into account, and to enable comparisons of effects in middle-age and different stages of older adulthood in line with previous studies examining participants throughout the adult lifespan [80, 81, 82]. Distributions for BMI, WHR, and BF\% within each Age Group are shown in SI Figure 2.

Table 2: Number of participants in each Menopause Age Group and each Age group, separated by sex and with \% of $\mathrm{APOE}_{4}$ carriers in brackets.

\begin{tabular}{lrc}
\hline \multicolumn{3}{c}{ Female } \\
\hline Menopause Age Group & $\mathrm{N}($ APOE4+) \\
\hline 40-45yrs & $986(27.48 \%)$ \\
46-50yrs & $2,842(26.39 \%)$ \\
$51-55 y r s$ & $4,059(27.32 \%)$ \\
$56-62 y r s$ & $883(25.93 \%)$ \\
\hline \multicolumn{3}{c}{ Female } \\
\hline Age Group & $\mathrm{N}($ APOE4+) & $\mathrm{N}($ APOE $4+)$ \\
\hline 45-55yrs & $1,049(29.26 \%)$ & $1,651(26.95 \%)$ \\
$56-65 y r s$ & $4,127(27.16 \%)$ & $3,716(25.61 \%)$ \\
$66-82 \mathrm{yrs}$ & $3,594(25.90 \%)$ & $5,238(24.91 \%)$ \\
\hline
\end{tabular}

To test if results were consistent between Menopause Age Group and Age Group bins and the continuous measures of these variables, we conducted supplementary analyses using the continuous variables of Age at Menopause and Age. 


\subsection{Statistical analyses}

The statistical analyses were conducted using Python 3.7.6 and $\mathrm{R}$ version 3.5. All variables were standardized (subtracting the mean and dividing by the SD) before being entered into the analyses. $P$-values were corrected for multiple comparisons using false discovery rate (FDR) correction [124]. We report the $F$-test significance of each main effect and each interaction, as $F$ is useful for interpreting models containing categorical variables with more than two levels. The $F$-statistics were generated in $\mathrm{R}$ by adding the Anova wrapper function to the linear model $(l m)$ of interest.

We first determined whether there were sex differences in the effects of CMRs and $A P O E$ genotype on WM BAG, with the dependent variable representing BAG values based on the mixed-sex age prediction model $\left(B A G_{m s}\right)$. In order to adjust for age-dependence in CMRs and $\mathrm{APOE}_{4}$ status, age was included as a covariate. The following $l m$ was used for these analyses, with $x$ representing each CMR (BMI, WHR, BF\%) or APOE4 status, respectively:

$$
B A G_{m s} \sim x \times S e x+A g e .
$$

To test if interactions between sex and CMRs varied according to APOE 4 status, the following $l m$ was used with $C M R$ representing each risk factor (BMI, WHR, BF\%):

$$
B A G_{m s} \sim C M R \times S e x \times A P O E+A g e .
$$

We then used the BAG values from the female-specific model to determine whether CMR and $A P O E$ effects on BAG varied according to age at menopause in females (Menopause Age Group). The following $l m$ was used for these analyses, with $B A G_{s s}$ representing BAG estimates based on the sex-specific model, and $x$ representing each CMR or APOE4 status, respectively:

$$
B A G_{s s} \sim x \times \text { Menopause Age Group }+ \text { Age. }
$$

To test if interactions between Menopause Age Group and CMR varied according to APOE genotype, the following $l m$ was used with $C M R$ representing each risk factor:

$$
B A G_{s s} \sim C M R \times \text { Menopause Age Group } \times \text { APOE }+ \text { Age } .
$$


To determine whether effects in females and males varied across age bins, we ran analyses within each sex assessing the interactions of CMRs, $A P O E$ genotype, and Age Group on BAG. Sex-specific BAG values were used as dependent variables in the following $l m$, with $x$ representing each CMR or $A P O E 4$ status, respectively:

$$
B A G_{s s} \sim x \times \text { Age Group } .
$$

To test if interactions between Age Group and CMRs varied according to APOE genotype, the following $l m$ was used with $C M R$ representing each risk factor:

$$
B A G_{s s} \sim C M R \times \text { Age Group } \times \text { APOE } .
$$

As a follow-up, we ran the following $l m$ within each of the Age Groups (for each sex) adjusting for effects of age within each Age Group bin:

$$
B A G_{s s} \sim C M R \times A P O E+A g e .
$$

\section{Results}

\subsection{Brain age prediction}

The accuracy of the age prediction models are shown in Table 3. SI Tables 1 and 2 depict the top $10 \mathrm{WM}$ features for the mixed-sex and sex-specific age predictions, with the majority of the features overlapping between the three models.

Table 3: Age prediction accuracy for the mixed-sex and sex-specific models, including average $\mathrm{R}^{2}$, root mean square error (RMSE), mean absolute error (MAE), and correlations $(r)$ between predicted and chronological age. $\mathrm{CI}=$ confidence interval.

\begin{tabular}{lccccc}
\hline Model & $\mathrm{R}^{2}$ & RMSE & MAE & $r[95 \% \mathrm{CI}]$ & $p$ \\
\hline Mixed $(\mathrm{N}=35,740)$ & $0.51 \pm 0.009$ & $5.27 \pm 0.007$ & $4.23 \pm 0.005$ & $0.72[0.71,0.72]$ & $<0.0001$ \\
\hline Male $(\mathrm{N}=16,909)$ & $0.50 \pm 0.017$ & $5.39 \pm 0.115$ & $4.34 \pm 0.080$ & $0.71[0.70,0.72]$ & $<0.0001$ \\
\hline Female $(\mathrm{N}=18,831)$ & $0.49 \pm 0.015$ & $5.28 \pm 0.081$ & $4.27 \pm 0.070$ & $0.69[0.69,0.70]$ & $<0.0001$ \\
\hline
\end{tabular}




\subsection{Sex differences in effects of CMRs and APOE genotype on WM BAG}

To assess sex differences in the associations between $\mathrm{BAG}$ and $\mathrm{BMI}, \mathrm{WHR}, \mathrm{BF} \%$, and $A P O E 4$ status, we tested for sex-interactions as described in Section 2.7. The analyses revealed significant interaction effects of $S e x * B M I, S e x * W H R$, and $S e x * B F \%$ on BAG, as shown in Table 4 and Figure 2. Greater WHR was associated with higher BAG (older brain age relative to chronological age) across sexes, but the effect was more prominent in males compared to females. BF\% showed diverging associations, with higher values related to higher BAG in males and higher values related to lower BAG (younger brain age relative to chronological age) in females. Higher BMI values were associated with higher BAG in males, while no significant effect of BMI was seen in females. We observed no significant main effects of $A P O E$ genotype, and no significant interactions between $A P O E$ genotype and Sex or CMRs (see SI Table 3 for full results). Figure 2 shows the beta values for the BAG associations with each CMR and $A P O E$ 4 status for both sexes, and for males and females separately. For comparison, we produced the same plot using estimates based on the sex-specific models (BAG values estimated relative to sex-specific age trajectories), as shown in SI Figure 1. The results showed similar patterns, with associations between higher BAG and greater BMI, WHR, and BF\% in males, and between higher BAG and greater WHR, but not BMI and $\mathrm{BF} \%$, in females.

Table 4: Sex differences in the associations between Brain Age Gap and body mass index (BMI), waist-tohip-ratio (WHR), body fat percentage (BF\%), and APOE4 status based on formula 1 in Section 2.7. Degrees of freedom $=(1,21303)$.

\begin{tabular}{llll}
\hline Interaction & $\boldsymbol{F}$ & $\boldsymbol{p}$ & pcorr \\
\hline Sex $\times$ BMI & 29.15 & $6.76 \times 10^{-8}$ & $1.35 \times 10^{-7}$ \\
\hline Sex $\times W H R$ & 11.45 & $7.2 \times 10^{-4}$ & $9.56 \times 10^{-4}$ \\
\hline Sex $\times$ BF\% & 43.37 & $4.65 \times 10^{-11}$ & $1.86 \times 10^{-10}$ \\
\hline Sex $\times A P O E$ & 0.93 & 0.34 & 0.34 \\
\hline
\end{tabular}




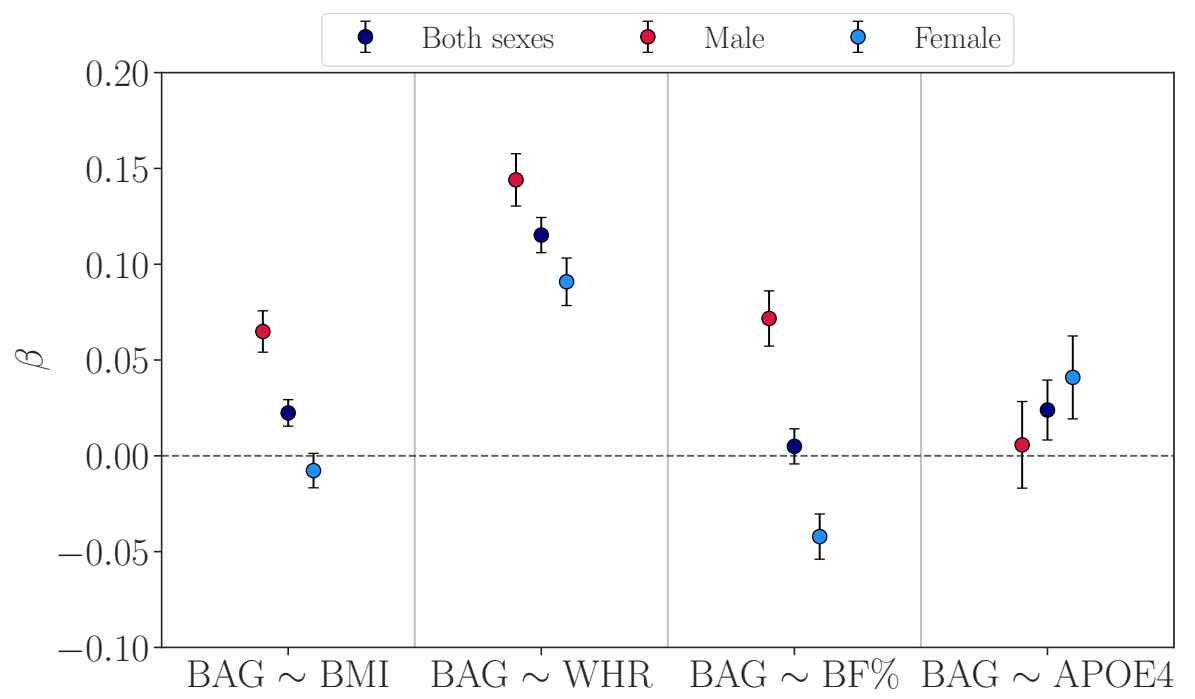

Figure 2: Associations between WM Brain Age Gap (BAG) and each cardiometabolic risk factor as well as $\mathrm{APOE}_{4}$ status for both sexes, and for males and females separately. $\beta$ (y-axis) represents the beta value (slope) for each association, e.g., a positive $\beta$ value indicates an association between greater cardiometabolic measures or $\mathrm{APOE}_{4}$ and higher $\mathrm{BAG}$ (older brain age relative to chronological age). The error bars represent standard errors on the $\beta$. BMI = body mass index, WHR = waist-to-hip ratio, $\mathrm{BF} \%=$ body fat percentage.

\subsection{Sex- and age-specific effects of CMRs and APOE genotype on WM BAG}

To assess whether effects of CMRs and $\mathrm{APOE}_{4}$ status varied according to age at menopause or across specific age periods, we next performed a series of regressions testing for interactions with Menopause Age Group in females and Age Group in males and females separately, as described in Sections 2.6 and 2.7.

\subsubsection{Effects of Menopause Age Group $\times$ CMRs and APOE genotype on WM BAG}

In females, no interactions of CMR measures and $\mathrm{APOE}_{4}$ status with Menopause Age Group were found, as shown in Table 5. The results were consistent when using the continuous Age at Menopause variable, as shown in SI Table 5. Across models, there was a main effect of Menopause Age Group such that a lower age at menopause was associated with higher WM BAG (see SI Table 4 and SI Figure 2). This effect was consistent when using the continuous Age at Menopause variable in a regression model including hormone replacement therapy use, education, income, Townsend Deprivation Index, alcohol intake, physical activity, and number of childbirths in addition to age, BMI, and APOE4 status as covariates $\left(\beta=-0.036 \pm 0.010, p=1.40 \times 10^{-4}\right.$; see SI Section 6 for details about the covariates $)$. 
Table 5: The interaction between Menopause Age Group and body mass index (BMI), waist-to-hip-ratio (WHR), body fat percentage (BF\%), and APOE4 status on Brain Age Gap in females (formula 3, Section $2.7)$. Degrees of freedom $=(3,8761)$.

\begin{tabular}{llll}
\hline Interaction & $\boldsymbol{F}$ & $\boldsymbol{p}$ & pcorr \\
\hline$B M I \times$ Menopause Age Group & 2.00 & 0.11 & 0.22 \\
\hline$W H R \times$ Menopause Age Group & 1.50 & 0.21 & 0.28 \\
\hline$B F \% \times$ Menopause Age Group & 2.08 & 0.10 & 0.22 \\
\hline$A P O E \times$ Menopause Age Group & 0.73 & 0.53 & 0.53 \\
\hline
\end{tabular}

\subsubsection{Effects of Age Group $\times$ CMRs and APOE genotype on WM BAG}

To assess whether effects of CMRs and $A P O E 4$ status varied across specific age periods, we applied regressions including interaction terms with Age Group as described in formula 5, Section 2.7. For both females and males, no significant effects were found for Age Group $\times$ CMR measures/APOE4 status on BAG (Table 6 and SI Table 6), indicating that the BAG associations with each CMR did not vary significantly between age groups. The results were consistent when using the continuous Age variable (SI Table 7). Figure 3 shows the associations between BAG and each CMR within each Age Group, and SI Figure 5 shows the associations grouped by $A P O E$ genotype.

Table 6: The interaction between Age Group and BMI, WHR, BF\%, and APOE genotype on Brain Age Gap (formula 5 , Section 2.7). Degrees of freedom $=(2,10599)$ and $(2,8764)$ for females and males, respectively.

\begin{tabular}{llll|lll}
\hline & \multicolumn{3}{c}{ Female } & \multicolumn{3}{c}{ Male } \\
\hline Interaction & $\boldsymbol{F}$ & $\boldsymbol{p}$ & $\boldsymbol{p c o r r}$ & $\boldsymbol{F}$ & $\boldsymbol{p}$ & pcorr \\
\hline$B M I \times$ Age Group & 1.96 & 0.14 & 0.25 & 2.33 & 0.10 & 0.39 \\
\hline$W H R \times$ Age Group & 1.68 & 0.19 & 0.25 & 0.72 & 0.49 & 0.49 \\
\hline$B F \% \times$ Age Group & 1.76 & 0.17 & 0.25 & 1.27 & 0.28 & 0.49 \\
\hline$A P O E \times$ Age Group & 0.31 & 0.73 & 0.73 & 0.87 & 0.42 & 0.49 \\
\hline
\end{tabular}



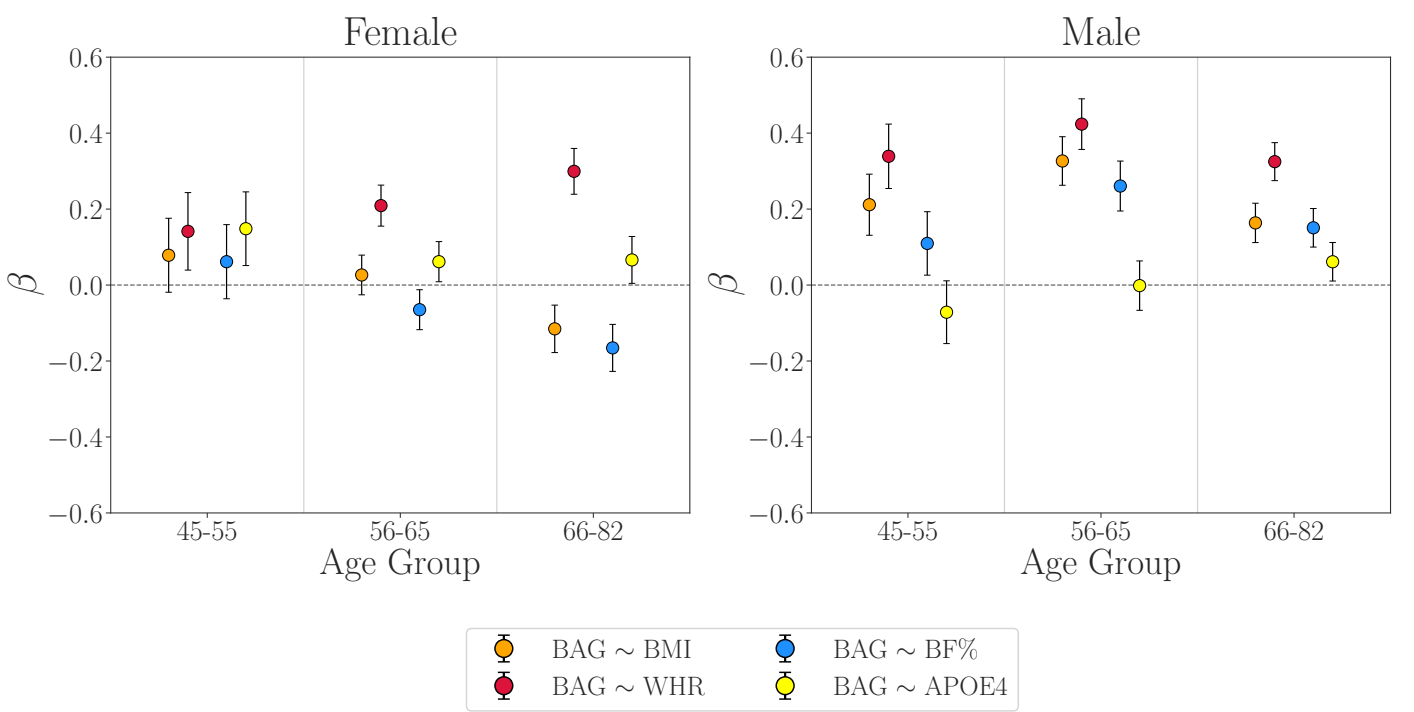

Figure 3: Associations between WM BAG and cardiometabolic risk factors as well as APOE4 status within each Age Group bin (formula 7, Section 2.7). $\beta$ (y-axis) represents the beta value (slope) for each association. The error bars represent standard errors on the $\beta$. BMI = body mass index, WHR waist-to-hip ratio, BF\% = body fat percentage.

While the BAG associations with each CMR were not significantly different between age groups (Table 6), the follow-up regression analyses within each age group indicated that the divergence between the associations with WHR versus BMI/BF\% increased with older age in females (Figure 3; see SI Tables 8 and 9 for full results). As a post-hoc test, we estimated the differences between the WHR vs. BMI/BF\% associations for females within each age group using a $Z$ test for correlated samples, as described in SI Section 7. The results confirmed that the divergence between the BAG associations with WHR versus BMI/BF\% increased with age, and was most prominent in the oldest age group (SI Table 10). 


\section{Discussion}

This study investigated whether associations between BAG and CMRs and APOE genotype varied i) between males and females, ii) according to age at menopause in females, and iii) across different age groups in males and females. In summary, the results showed sex differences in associations between BAG and all three CMRs, with stronger positive associations among males compared to females. Higher BAG (older brain age relative to chronological age) was associated with greater BMI, WHR, and BF\% in males, whereas in females, higher BAG was associated with greater WHR, but not BMI and BF\%. Earlier age at menopause was linked to higher BAG in females, but no interactions were found between age at menopause and CMRs. While none of the associations between BAG and each CMR were significantly different between age groups, follow-up analyses indicated that the divergence between the WHR and $\mathrm{BMI} / \mathrm{BF} \%$ associations observed in females was most prominent within the oldest age group (66-81yrs). APOE4 status showed no significant main effects on BAG, no age- or age at menopause-specific effects, and no significant interactions with CMRs. The findings demonstrate sex-specific associations between body fat composition and brain age, emphasizing the importance of analyzing males and females separately in studies addressing cardiometabolic risk in aging.

The analyses including sex as an interaction term showed that all three CMRs were associated with higher BAG in males relative to females. These findings support a recent study, which revealed that males may be more vulnerable than females to white matter brain aging in the presence of greater BMI [4] and, more broadly, greater cardiometabolic burden [7, 26, 27, 28]. Furthermore, sex differences in adipose fat distribution may differentially contribute to brain age, with males more likely having fat distributed in the visceral adipose tissue surrounding the abdominal organs, while females tend to have more subcutaneous adipose tissue [125, 126]. Compared to the latter, greater visceral adipose fat distribution is associated with elevated risk of cardiometabolic disease. In females, differential effects of $\mathrm{BF} \%$ and BMI compared to WHR were observed, with divergent associations particularly prominent in the oldest age group (66-82yrs) where lower BF\% was linked to higher BAG. This could reflect that lower $\mathrm{BF} \%$ in older females may be an indicator of frailty and preclin- 
ical dementia, and/or indicate a protective role of certain sources of adipose fat in females at later ages [43, 44, 45, 48]. While our results showed that earlier menopause transition was associated with greater BAG, we found no significant interactions between age at menopause and CMRs. Further longitudinal work is required to clarify the role of adipose tissue in female brain health, and how it may relate to sex-specific factors including the menopausal transition.

The evidence for the role of endogenous estrogen exposure in neurodegeneration and AD is controversial, with some studies reporting an association between shorter reproductive span and greater dementia risk (e.g., [127], while others have found that a longer reproductive span (i.e., later age of menopause) did not confer protective effects (e.g., [128, 129, 130]. Some studies have reported genotype-specific effects, with a longer reproductive span conferring greater risk in $\mathrm{APOE}_{4}$ carriers [130], and older brain age linked to greater menopausal levels of estradiol in APOE4 carriers and lower levels in non-carriers [131]. These studies point to a possible modulatory role of estrogen exposure [132], typically having beneficial effects, but potentially becoming neurotoxic in the context of greater AD pathology [133] or diseased cell populations (i.e., 'healthy cell' hypothesis [134]). While future studies including detailed data about the menopausal transition (i.e., pre-, peri, post menopause) as well as specific measures of AD-related brain pathology [135] are required to test these hypotheses, our findings showed a small but significant association between earlier menopause transition and higher WM BAG in the current cohort, in line with studies linking a shorter reproductive span to risk for neurodegeneration [127, 130, 136, 137, 138, 139].

Unlike females, in which menses cessation is a marker of menopause status, males have a more gradual endocrine aging process, with no significant marker for age at andropause. Although low levels of body fat in older age may be an indicator of frailty in both sexes [43, 44], our results show that in this sample, greater WHR, BMI, and BF\% were consistently linked to higher BAG in males. This corresponds with previous studies reporting negative effects of higher body fat levels on brain health in males across midlife and older ages [140, 141]. The male endocrine aging process typically involves gradual declines in testosterone levels. 
Greater adipose tissue may increase levels of aromatase, an enzyme that converts testosterone to estrogen, which in males may be associated with their accelerated endocrine and consequently, brain aging process $[142,143,144]$. Therefore, while greater adipose tissue can potentially act as a source of estrogen in post-menopausal females, it can be detrimental to males, in whom this may result in reduced testosterone levels (see [144] demonstrating that the genetic architecture of testosterone contributes to sex differences in cardiometabolic traits in the UK Biobank). Importantly, increasing evidence points to the role of sex hormones in mediating cerebrovascular function, in which dysregulation is linked to cerebrovascular diseases, cognitive impairment, and dementia (see reviews by [145, 146]). Further research on the links between sex hormones and cardiometabolic factors in endocrine aging may help inform sex-specific health interventions for both males and females.

No significant effects were found for $A P O E$ genotype. This is in line with our previous study showing no effects of $A P O E 4$ status or polygenic risk for $\mathrm{AD}$ on grey-matter based brain age in the UK Biobank sample [131], as well as a recent UK Biobank study showing that $A P O E 4+$ genotype was associated with WM hyperintensities, but not with FA or MD in WM tracts [147]. While our age prediction was based on several diffusion models known to be sensitive to WM aging [73, 84, 89], it is possible that specific estimates of WM hyperintensities could yield $A P O E$-sensitive CMR associations. Furthermore, a recent UK Biobank study revealed region- and metric-specific effects of age and sex on WM microstructure [148]. Although age prediction models combine a rich variety of WM characteristics into single estimates, global BAG estimates do not provide specific information about regional WM connections. Hence, future studies may aim to investigate regional and diffusion metricspecific estimates of brain aging in relation to $A P O E$ genotype and CMRs. Modality-specific BAG estimates are also relevant for identifying differences in brain tissue affected by a specific condition or disease [1, 55, 68, 72]. For example, one of our previous studies found that BMI interacted with AD risk to influence grey-matter based BAG, such that females with greater AD risk benefited more from a higher BMI [45]. While the current study focused on WM measures given their susceptibility to CMRs, future studies may aim to include several brain modalities to directly compare sex- and age-specific effects. More detailed measures 
of fat distribution obtained with body MRI [76, 149, 150, 151] may also clarify the divergent associations observed in females, and provide a more complete understanding of adipose tissue distribution in relation to cardiometabolic disease [150, 152], AD risk [153], and endocrine aging processes [154]. Due to sample size restrictions in relation to our study goals of determining sex- and age-specific effects, we could not currently probe body MRI in our subgroups, but ongoing data collection of this measure from UK Biobank participants will render future analyses of these measures feasible.

Although the large UK Biobank cohort enabled us to investigate whether effects were sensitive to specific age- or age at menopause periods, the sample sizes were limited by probing variables with different subgroups (i.e., dividing our sample across sex, APOE genotype, and Menopause/Age Group levels). However, our sub-group samples (n>250) are still large compared to the majority of previous studies investigating sex- or age-specific effects on brain structure [155]. The results also highlight potential causes of mixed findings in the literature: variations in associations reported across studies could be due to not separating analyses by sex (see Figure 2), investigating samples with different age ranges (see Figure 3 and and SI Table 8), and/or the use of different CMRs. As participant re-testing of the UK Biobank baseline cohort is actively underway, our future work will aim to integrate longitudinal investigations of brain age, as the current cross-sectional analyses prevent any conclusions about causality. Longitudinal designs may also enable differentiation between age-specific effects and effects that emerge as a result of a selective attrition or survival bias [34, 35, 36, 37]. While UK Biobank provides an excellent resource of open-access population health data, the cohort is homogeneous with regard to ethnic background and education, and characterized by a 'healthy volunteer effect' [156], indicating that it is not representative of the general population [157]. Although the current results may not generalize to populations beyond those represented in this cohort, our findings may prompt further study into sex- and age-specific effects of cardiometabolic risk as well as endocrine aging. Lastly, since neural aging processes are multi-factorial, single risk factors can only explain parts of the individual variation. Hence, future studies may aim to go beyond investigating risk factors in isolation and adopt approaches that can model complex relationships between a variety of 
gene-environment interactions and brain health in aging [158, 159].

In conclusion, this study demonstrates notable sex differences in associations between body fat indices and WM brain age, underlining the importance of stratifying samples by sex in population-based and clinical studies [160, 161, 162, 163, 164, 165]. Independent of cardiometabolic profile, earlier menopause transition was associated with higher BAG in females. Hence, considering effects of both chronological and endocrine aging may increase our understanding of sex-specific brain aging trajectories and disease prevalence [166, 167]. Given the historical lack of research into sex-specific influences on brain health and disease [96, 168, 166, 169], future studies incorporating sex as a variable of interest may provide valuable contributions to precision medicine research, consequently improving health care for both males and females.

\section{Data availability statement}

The data that support the findings of this study are available through the UK Biobank data access procedures (https://www.ukbiobank.ac.uk/researchers). Code for running the age prediction models is available at https://github.com/amdelange/brainage_women.

\section{Acknowledgements}

This research has been conducted using the UK Biobank under Application 27412. UKB has received ethics approval from the National Health Service National Research Ethics Service (ref 11/NW/0382). The work was performed on the Service for Sensitive Data (TSD) platform, owned

by the University of Oslo, operated and developed by the TSD service group at the University of Oslo IT-Department (USIT). Computations were also performed using resources provided by UNINETT Sigma2 - the National Infrastructure for High Performance Computing and Data Storage in Norway. While working on this study, the authors received funding from the Women in Cognitive Science-Canada (S. Subramaniapillai), NSERC Michael Smith Foreign Study Supplement (S. Subramaniapillai), Healthy Brains Healthy Lives (S. Subramaniapillai), the Alzheimer's Society (S. Suri; 441), the Academy of Medical Sciences/the Wellcome Trust/the Government Department of Business, Energy and Industrial Strategy/the British Heart Foundation/Diabetes UK Springboard Award (S. Suri; SBF006 \1078), the Research Council of Norway (L.T. Westlye; 273345, 249795, 298646, 300768, 223273; O.A. Andreassen; 223273, 283799, 2837989), the South-East Norway Regional Health Authority (L.T. Westlye; 2018076, 2019101, O.A. Andreassen; 2019-108, 2017-112), 
the European Research Council under the European Union's Horizon 2020 research and innovation programme (L.T. Westlye; 802998, O.A. Andreassen.; 847776, K.P. Ebmeier; 732592), the HDH Wills 1965 Charitable Trust (K.P. Ebmeier.; 1117747), the Leenaards Foundation (B. Draganski), and the Swiss National Science Foundation (AM.G. de Lange.; PZ00P3_193658; B. Draganski; NCCR Synapsy, project grants Nr 32003B_135679, 32003B_159780, 324730_192755, and CRSK3_190185). The Wellcome Centre for Integrative Neuroimaging is supported by core funding from the Wellcome Trust (203139/Z/16/Z).

\section{References}

[1] D. Beck, A.-M. G. de Lange, M. L. Pedersen, D. Alnæs, I. I. Maximov, I. Voldsbekk, G. Richard, A.-M. Sanders, K. M. Ulrichsen, E. S. Dørum, K. K. Kolskår, E. A. Høgestøl, N. E. Steen, S. Djurovic, O. A. Andreassen, J. E. Nordvik, T. Kaufmann, L. T. Westlye, Cardiometabolic risk factors associated with brain age and accelerate brain ageing, Human Brain Mapping n/a (2021).

[2] C. Qiu, L. Fratiglioni, A major role for cardiovascular burden in age-related cognitive decline, Nature Reviews Cardiology 12 (2015) 267-277.

[3] G. Livingston, J. Huntley, A. Sommerlad, D. Ames, C. Ballard, S. Banerjee, C. Brayne, A. Burns, J. Cohen-Mansfield, C. Cooper, et al., Dementia prevention, intervention, and care: 2020 report of the lancet commission, The Lancet 396 (2020) 413-446.

[4] A. Alqarni, J. Jiang, J. D. Crawford, F. Koch, H. Brodaty, P. Sachdev, W. Wen, Sex differences in risk factors for white matter hyperintensities in non-demented older individuals, Neurobiology of aging 98 (2021) 197-204.

[5] E. Gerdts, V. Regitz-Zagrosek, Sex differences in cardiometabolic disorders, Nature medicine 25 (2019) 1657-1666.

[6] M. Schorr, L. E. Dichtel, A. V. Gerweck, R. D. Valera, M. Torriani, K. K. Miller, M. A. Bredella, Sex differences in body composition and association with cardiometabolic risk, Biology of sex differences 9 (2018) 1-10.

[7] M. I. Geerlings, A. P. Appelman, K. L. Vincken, A. Algra, T. D. Witkamp, W. P. Mali, Y. van der Graaf, S. S. Group, et al., Brain volumes and cerebrovascular lesions on mri in patients with atherosclerotic disease. the smart-mr study, Atherosclerosis 210 (2010) 130-136.

[8] P. Bretsky, J. Buckwalter, T. Seeman, C. Miller, J. Poirier, G. Schellenberg, C. Finch, V. Henderson, Evidence for an interaction between apolipoprotein e genotype, gender, and alzheimer disease., Alzheimer disease and associated disorders (1999).

[9] S. C. Neu, J. Pa, W. Kukull, D. Beekly, A. Kuzma, P. Gangadharan, L.-S. Wang, K. Romero, S. P. Arneric, A. Redolfi, et al., Apolipoprotein e genotype and sex risk factors for alzheimer disease: a meta-analysis, JAMA neurology 74 (2017) 1178-1189.

[10] G. Dubnov, A. Brzezinski, E. M. Berry, Weight control and the management of obesity after menopause: the role of physical activity, Maturitas 44 (2003) 89-101. 
[11] A. H. Maas, Y. E. Appelman, Gender differences in coronary heart disease, Netherlands Heart Journal 18 (2010) 598-603.

[12] F. J. Alfaro, A. Gavrieli, P. Saade-Lemus, V.-A. Lioutas, J. Upadhyay, V. Novak, White matter microstructure and cognitive decline in metabolic syndrome: a review of diffusion tensor imaging, Metabolism 78 (2018) 52-68.

[13] K. Mueller, A. Anwander, H. E. Möller, A. Horstmann, J. Lepsien, F. Busse, S. Mohammadi, M. L. Schroeter, M. Stumvoll, A. Villringer, et al., Sex-dependent influences of obesity on cerebral white matter investigated by diffusion-tensor imaging, PloS one 6 (2011) e18544.

[14] K. M. Stanek, S. M. Grieve, A. M. Brickman, M. S. Korgaonkar, R. H. Paul, R. A. Cohen, J. J. Gunstad, Obesity is associated with reduced white matter integrity in otherwise healthy adults, Obesity 19 (2011) 500-504.

[15] A. C. Birdsill, S. Oleson, S. Kaur, E. Pasha, A. Ireton, H. Tanaka, A. Haley, Abdominal obesity and white matter microstructure in midlife, Human brain mapping 38 (2017) 3337-3344.

[16] O. Trofimova, L. Loued-Khenissi, G. DiDomenicantonio, A. Lutti, M. Kliegel, S. Stringhini, P. Marques-Vidal, P. Vollenweider, G. Waeber, M. Preisig, et al., Brain tissue properties link cardio-vascular risk factors, mood and cognitive performance in the colaus| psycolaus epidemiological cohort, Neurobiology of Aging 102 (2021) 50-63.

[17] L. Griffanti, M. Jenkinson, S. Suri, E. Zsoldos, A. Mahmood, N. Filippini, C. E. Sexton, A. Topiwala, C. Allan, M. Kivimäki, et al., Classification and characterization of periventricular and deep white matter hyperintensities on mri: a study in older adults, Neuroimage 170 (2018) 174-181.

[18] L. Lampe, R. Zhang, F. Beyer, S. Huhn, S. Kharabian Masouleh, S. Preusser, P.-L. Bazin, M. L. Schroeter, A. Villringer, A. V. Witte, Visceral obesity relates to deep white matter hyperintensities via inflammation, Annals of neurology 85 (2019) 194-203.

[19] M. Habes, A. Sotiras, G. Erus, J. B. Toledo, D. Janowitz, D. A. Wolk, H. Shou, N. R. Bryan, J. Doshi, H. Völzke, et al., White matter lesions: spatial heterogeneity, links to risk factors, cognition, genetics, and atrophy, Neurology 91 (2018) e964-e975.

[20] P. S. Sachdev, R. Parslow, W. Wen, K. Anstey, S. Easteal, Sex differences in the causes and consequences of white matter hyperintensities, Neurobiology of aging 30 (2009) 946-956.

[21] L. M. Raffield, A. J. Cox, B. I. Freedman, C. E. Hugenschmidt, F.-C. Hsu, B. C. Wagner, J. Xu, J. A. Maldjian, D. W. Bowden, Analysis of the relationships between type 2 diabetes status, glycemic control, and neuroimaging measures in the diabetes heart study mind, Acta diabetologica 53 (2016) 439-447.

[22] F. De Leeuw, J. C. de Groot, E. Achten, M. Oudkerk, L. Ramos, R. Heijboer, A. Hofman, J. Jolles, J. Van Gijn, M. Breteler, Prevalence of cerebral white matter lesions in elderly people: a population based magnetic resonance imaging study. the rotterdam scan study, Journal of Neurology, Neurosurgery \& Psychiatry 70 (2001) 9-14.

[23] C. DeCarli, J. Massaro, D. Harvey, J. Hald, M. Tullberg, R. Au, A. Beiser, R. D'Agostino, P. A. Wolf, Measures of brain morphology and infarction in the framingham heart study: establishing what is normal, Neurobiology of aging 26 (2005) 491-510. 
[24] F. Fatemi, K. Kantarci, J. Graff-Radford, G. M. Preboske, S. D. Weigand, S. A. Przybelski, D. S. Knopman, M. M. Machulda, R. O. Roberts, M. M. Mielke, et al., Sex differences in cerebrovascular pathologies on flair in cognitively unimpaired elderly, Neurology 90 (2018) e466-e473.

[25] D. Van Den Heuvel, F. Admiraal-Behloul, V. Ten Dam, H. Olofsen, E. Bollen, H. Murray, G. Blauw, R. Westendorp, A. De Craen, M. Van Buchem, et al., Different progression rates for deep white matter hyperintensities in elderly men and women, Neurology 63 (2004) 16991701.

[26] A. A. Assareh, K. A. Mather, J. D. Crawford, W. Wen, K. J. Anstey, S. Easteal, X. Tan, H. A. Mack, J. B. Kwok, P. R. Schofield, et al., Renin-angiotensin system genetic polymorphisms and brain white matter lesions in older australians, American journal of hypertension 27 (2014) 1191-1198.

[27] J. Filomena, I. Riba-Llena, E. Vinyoles, J. L. Tovar, X. Mundet, X. Castañé, A. Vilar, A. López-Rueda, J. Jiménez-Baladó, A. Cartanyà, et al., Short-term blood pressure variability relates to the presence of subclinical brain small vessel disease in primary hypertension, Hypertension 66 (2015) 634-640.

[28] C. Jongen, J. Van Der Grond, L. Kappelle, G. Biessels, M. Viergever, J. Pluim, Automated measurement of brain and white matter lesion volume in type 2 diabetes mellitus, Diabetologia 50 (2007) 1509-1516.

[29] A. Solomon, M. Kivipelto, B. Wolozin, J. Zhou, R. A. Whitmer, Midlife serum cholesterol and increased risk of alzheimer's and vascular dementia three decades later, Dementia and geriatric cognitive disorders 28 (2009) 75-80.

[30] P. van Vliet, Cholesterol and late-life cognitive decline, Journal of Alzheimer's Disease 30 (2012) S147-S162.

[31] C. Qiu, B. Winblad, L. Fratiglioni, The age-dependent relation of blood pressure to cognitive function and dementia, The Lancet Neurology 4 (2005) 487-499.

[32] R. Stewart, K. Masaki, Q.-L. Xue, R. Peila, H. Petrovitch, L. R. White, L. J. Launer, A 32-year prospective study of change in body weight and incident dementia: the honolulu-asia aging study, Archives of neurology 62 (2005) 55-60.

[33] A. L. Fitzpatrick, L. H. Kuller, O. L. Lopez, P. Diehr, E. S. O’Meara, W. Longstreth, J. A. Luchsinger, Midlife and late-life obesity and the risk of dementia: cardiovascular health study, Archives of neurology 66 (2009) 336-342.

[34] A. L. Heffernan, C. Chidgey, P. Peng, C. L. Masters, B. R. Roberts, The neurobiology and agerelated prevalence of the $\varepsilon 4$ allele of apolipoprotein e in alzheimer's disease cohorts, Journal of Molecular Neuroscience 60 (2016) 316-324.

[35] M. R. Munafò, K. Tilling, A. E. Taylor, D. M. Evans, G. Davey Smith, Collider scope: when selection bias can substantially influence observed associations, International journal of epidemiology 47 (2018) 226-235. 
[36] E. Jacobsen, X. Ran, A. Liu, C.-C. H. Chang, M. Ganguli, Predictors of attrition in a longitudinal population-based study of aging, International psychogeriatrics 33 (2021) 767778.

[37] T. A. Salthouse, Selectivity of attrition in longitudinal studies of cognitive functioning, Journals of Gerontology Series B: Psychological Sciences and Social Sciences 69 (2014) 567-574.

[38] C. J. Lavie, A. De Schutter, D. A. Patel, A. Romero-Corral, S. M. Artham, R. V. Milani, Body composition and survival in stable coronary heart disease: impact of lean mass index and body fat in the "obesity paradox", Journal of the American College of Cardiology 60 (2012) 1374-1380.

[39] A. J. Tomiyama, J. M. Hunger, J. Nguyen-Cuu, C. Wells, Misclassification of cardiometabolic health when using body mass index categories in nhanes 2005-2012, International journal of obesity 40 (2016) 883-886.

[40] R. Huxley, S. Mendis, E. Zheleznyakov, S. Reddy, J. Chan, Body mass index, waist circumference and waist: hip ratio as predictors of cardiovascular risk-a review of the literature, European journal of clinical nutrition 64 (2010) 16-22.

[41] A. Tchernof, J.-P. Després, Pathophysiology of human visceral obesity: an update, Physiological reviews (2013).

[42] M. Kivimäki, R. Luukkonen, G. D. Batty, J. E. Ferrie, J. Pentti, S. T. Nyberg, M. J. Shipley, L. Alfredsson, E. I. Fransson, M. Goldberg, et al., Body mass index and risk of dementia: analysis of individual-level data from 1.3 million individuals, Alzheimer's \& Dementia 14 (2018) 601-609.

[43] D. K. Johnson, C. H. Wilkins, J. C. Morris, Accelerated weight loss may precede diagnosis in alzheimer disease, Archives of neurology 63 (2006) 1312-1317.

[44] A. S. Buchman, R. S. Wilson, J. L. Bienias, R. C. Shah, D. A. Evans, D. A. Bennett, Change in body mass index and risk of incident alzheimer disease, Neurology 65 (2005) 892-897.

[45] S. Subramaniapillai, S. Rajagopal, J. Snytte, A. R. Otto, G. Einstein, M. N. Rajah, P.-A. R. Group, et al., Sex differences in brain aging among adults with family history of alzheimer's disease and apoe4 genetic risk, NeuroImage: Clinical 30 (2021) 102620.

[46] E. B. Hassan, C. Szoeke, S. Vogrin, S. Phu, V. Venkatraman, P. Desmond, C. Steward, G. Duque, Association between structural changes in brain with muscle function in sarcopenic older women: the women's healthy ageing project (whap), Journal of musculoskeletal \& neuronal interactions 19 (2019) 136.

[47] E. R. Simpson, Sources of estrogen and their importance, The Journal of steroid biochemistry and molecular biology 86 (2003) 225-230.

[48] L. P. Klosinski, J. Yao, F. Yin, A. N. Fonteh, M. G. Harrington, T. A. Christensen, E. Trushina, R. D. Brinton, White matter lipids as a ketogenic fuel supply in aging female brain: implications for alzheimer's disease, EBioMedicine 2 (2015) 1888-1904. 
[49] S. Trikudanathan, A. Pedley, J. M. Massaro, U. Hoffmann, E. W. Seely, J. M. Murabito, C. S. Fox, Association of female reproductive factors with body composition: the framingham heart study, The Journal of Clinical Endocrinology \& Metabolism 98 (2013) 236-244.

[50] M. Sowers, H. Zheng, K. Tomey, C. Karvonen-Gutierrez, M. Jannausch, X. Li, M. Yosef, J. Symons, Changes in body composition in women over six years at midlife: ovarian and chronological aging, The Journal of Clinical Endocrinology \& Metabolism 92 (2007) 895-901.

[51] J. H. Cole, R. E. Marioni, S. E. Harris, I. J. Deary, Brain age and other bodily 'ages': implications for neuropsychiatry, Molecular psychiatry 24 (2019) 266-281.

[52] J. H. Cole, K. Franke, Predicting age using neuroimaging: innovative brain ageing biomarkers, Trends in neurosciences 40 (2017) 681-690.

[53] T. Kaufmann, D. van der Meer, N. T. Doan, E. Schwarz, M. J. Lund, I. Agartz, D. Alnæs, D. M. Barch, R. Baur-Streubel, A. Bertolino, et al., Common brain disorders are associated with heritable patterns of apparent aging of the brain, Nature neuroscience 22 (2019) 16171623.

[54] J. Cole, J. Raffel, T. Friede, A. Eshaghi, W. Brownlee, D. Chard, N. De Stefano, C. Enzinger, L. Pirpamer, M. Filippi, et al., Accelerated brain ageing and disability in multiple sclerosis, bioRxiv (2019) 584888.

[55] J. Rokicki, T. Wolfers, W. Nordhøy, N. Tesli, D. S. Quintana, D. Alnæs, G. Richard, A.M. G. de Lange, M. J. Lund, L. Norbom, et al., Multimodal imaging improves brain age prediction and reveals distinct abnormalities in patients with psychiatric and neurological disorders, Human Brain Mapping (2020).

[56] S. Tønnesen, T. Kaufmann, A.-M. de Lange, G. Richard, N. T. Doan, D. Alnaes, D. van der Meer, J. Rokicki, T. Moberget, I. I. Maximov, et al., Brain age prediction reveals aberrant brain white matter in schizophrenia and bipolar disorder: A multi-sample diffusion tensor imaging study, bioRxiv (2020) 607754 .

[57] L. K. Han, R. Dinga, T. Hahn, C. R. Ching, L. T. Eyler, L. Aftanas, M. Aghajani, A. Aleman, B. T. Baune, K. Berger, et al., Brain aging in major depressive disorder: results from the ENIGMA major depressive disorder working group, Molecular Psychiatry (2020) 1-16.

[58] K. Franke, C. Gaser, Ten years of brainage as a neuroimaging biomarker of brain aging: What insights have we gained?, Frontiers in Neurology 10 (2019) 789.

[59] J. Wang, M. J. Knol, A. Tiulpin, F. Dubost, M. de Bruijne, M. W. Vernooij, H. H. Adams, M. A. Ikram, W. J. Niessen, G. V. Roshchupkin, Gray matter age prediction as a biomarker for risk of dementia, Proceedings of the National Academy of Sciences 116 (2019) 21213-21218.

[60] F. Biondo, A. Jewell, M. Pritchard, C. Mueller, C. J. Steves, J. Cole, Brain-age predicts subsequent dementia in memory clinic patients: Neuroimaging/optimal neuroimaging measures for early detection, Alzheimer's \& Dementia 16 (2020) e037378.

[61] L. C. Löwe, C. Gaser, K. Franke, A. D. N. Initiative, The effect of the apoe genotype on individual brainage in normal aging, mild cognitive impairment, and alzheimer's disease, PloS one 11 (2016) e0157514. 
[62] C. Gaser, K. Franke, S. Klöppel, N. Koutsouleris, H. Sauer, A. D. N. Initiative, Brainage in mild cognitive impaired patients: predicting the conversion to alzheimer's disease, PloS one 8 (2013) e67346.

[63] K. Franke, C. Gaser, Longitudinal changes in individual brainage in healthy aging, mild cognitive impairment, and alzheimer's disease, GeroPsych (2012).

[64] M. L. Elliott, D. W. Belsky, A. R. Knodt, D. Ireland, T. R. Melzer, R. Poulton, S. Ramrakha, A. Caspi, T. E. Moffitt, A. R. Hariri, Brain-age in midlife is associated with accelerated biological aging and cognitive decline in a longitudinal birth cohort, Molecular psychiatry (2019) 1-10.

[65] D. Vidal-Piñeiro, Y. Wang, S. K. Krogsrud, I. K. Amlien, W. F. Baaré, D. Bartrés-Faz, L. Bertram, A. M. Brandmaier, C. A. Drevon, S. Düzel, K. P. Ebmeier, et al., Individual variations in" brain age" relate to early life factors more than to longitudinal brain change, eLife (in press) (2021).

[66] M. Kolenic, K. Franke, J. Hlinka, M. Matejka, J. Capkova, Z. Pausova, R. Uher, M. Alda, F. Spaniel, T. Hajek, Obesity, dyslipidemia and brain age in first-episode psychosis, Journal of psychiatric research 99 (2018) 151-158.

[67] H. Van Gestel, K. Franke, J. Petite, C. Slaney, J. Garnham, C. Helmick, K. Johnson, R. Uher, M. Alda, T. Hajek, Brain age in bipolar disorders: Effects of lithium treatment, Australian \& New Zealand Journal of Psychiatry 53 (2019) 1179-1188.

[68] A.-M. G. De Lange, M. Anatürk, S. Suri, T. Kaufmann, J. H. Cole, L. Griffanti, E. Zsoldos, D. E. Jensen, N. Filippini, A. Singh-Manoux, et al., Multimodal brain-age prediction and cardiovascular risk: The whitehall ii mri sub-study, NeuroImage 222 (2020) 117292.

[69] N. Egorova, F. Liem, V. Hachinski, A. Brodtmann, Predicted brain age after stroke, Frontiers in aging neuroscience 11 (2019) 348.

[70] A. Kolbeinsson, S. Filippi, Y. Panagakis, P. M. Matthews, P. Elliott, A. Dehghan, I. Tzoulaki, Accelerated mri-predicted brain ageing and its associations with cardiometabolic and brain disorders, Scientific Reports 10 (2020) 1-9.

[71] F. Biondo, A. Jewell, M. Pritchard, D. Aarsland, C. J. Steves, C. Mueller, J. H. Cole, Brain-age predicts subsequent dementia in memory clinic patients, medRxiv (2021).

[72] J. H. Cole, Multi-modality neuroimaging brain-age in uk biobank: relationship to biomedical, lifestyle and cognitive factors, Neurobiology of Aging (2020).

[73] D. Beck, A.-M. De Lange, I. I. Maximov, G. Richard, O. A. Andreassen, J. E. Nordvik, L. T. Westlye, White matter microstructure across the adult lifespan: A mixed longitudinal and cross-sectional study using advanced diffusion models and brain-age prediction, NeuroImage 224 (2021) 117441.

[74] G. Richard, K. Kolskår, A.-M. Sanders, T. Kaufmann, A. Petersen, N. T. Doan, J. M. Sanchez, D. Alnaes, K. M. Ulrichsen, E. S. Dørum, et al., Assessing distinct patterns of cognitive aging using tissue-specific brain age prediction based on diffusion tensor imaging and brain morphometry, PeerJ 6 (2018) e5908. 
[75] I. Voldsbekk, C. Barth, I. I. Maximov, T. Kaufmann, D. Beck, G. Richard, T. Moberget, L. T. Westlye, A.-M. G. de Lange, A history of previous childbirths is linked to women's white matter brain age in midlife and older age, Human Brain Mapping (2021).

[76] D. Beck, A.-M. G. de Lange, D. Alnaes, I. I. Maximov, M. L. Pedersen, O. D. Leinhard, J. Linge, R. Simon, G. Richard, E. S. Dorum, et al., Adipose tissue distribution from body mri is associated with cross-sectional and longitudinal brain age in adults, medRxiv (2021).

[77] Z. Ul-Haq, D. J. Smith, B. I. Nicholl, B. Cullen, D. Martin, J. M. Gill, J. Evans, B. Roberts, I. J. Deary, J. Gallacher, et al., Gender differences in the association between adiposity and probable major depression: a cross-sectional study of 140,564 uk biobank participants, BMC psychiatry 14 (2014) 1-10.

[78] K. E. Bradbury, W. Guo, B. J. Cairns, M. E. Armstrong, T. J. Key, Association between physical activity and body fat percentage, with adjustment for bmi: a large cross-sectional analysis of uk biobank, BMJ open 7 (2017) e011843.

[79] K. Bowman, J. L. Atkins, J. Delgado, K. Kos, G. A. Kuchel, A. Ble, L. Ferrucci, D. Melzer, Central adiposity and the overweight risk paradox in aging: follow-up of 130,473 uk biobank participants, The American journal of clinical nutrition 106 (2017) 130-135.

[80] C. L. Grady, M. V. Springer, D. Hongwanishkul, A. R. McIntosh, G. Winocur, Age-related changes in brain activity across the adult lifespan, Journal of cognitive neuroscience 18 (2006) $227-241$.

[81] S. Subramaniapillai, M. N. Rajah, S. Pasvanis, D. Titone, Bilingual experience and executive control over the adult lifespan: The role of biological sex, Bilingualism: Language and Cognition 22 (2019) 733-751.

[82] S. Subramaniapillai, S. Rajagopal, A. Elshiekh, S. Pasvanis, E. Ankudowich, M. N. Rajah, Sex differences in the neural correlates of spatial context memory decline in healthy aging, Journal of cognitive neuroscience 31 (2019) 1895-1916.

[83] P. J. Basser, J. Mattiello, D. LeBihan, MR diffusion tensor spectroscopy and imaging, Biophysical journal 66 (1994) 259-267.

[84] J. H. Jensen, J. A. Helpern, A. Ramani, H. Lu, K. Kaczynski, Diffusional kurtosis imaging: the quantification of non-gaussian water diffusion by means of magnetic resonance imaging, Magnetic Resonance in Medicine: An Official Journal of the International Society for Magnetic Resonance in Medicine 53 (2005) 1432-1440.

[85] E. Fieremans, J. H. Jensen, J. A. Helpern, White matter characterization with diffusional kurtosis imaging, Neuroimage 58 (2011) 177-188.

[86] L. T. Westlye, K. B. Walhovd, A. M. Dale, A. Bjørnerud, P. Due-Tønnessen, A. Engvig, H. Grydeland, C. K. Tamnes, Y. Østby, A. M. Fjell, Life-span changes of the human brain white matter: diffusion tensor imaging (dti) and volumetry, Cerebral cortex 20 (2010) 20552068. 
[87] S. K. Krogsrud, A. M. Fjell, C. K. Tamnes, H. Grydeland, L. Mork, P. Due-Tønnessen, A. Bjørnerud, C. Sampaio-Baptista, J. Andersson, H. Johansen-Berg, et al., Changes in white matter microstructure in the developing brain - a longitudinal diffusion tensor imaging study of children from 4 to 11 years of age, Neuroimage 124 (2016) 473-486.

[88] A. B. Storsve, A. M. Fjell, A. Yendiki, K. B. Walhovd, Longitudinal changes in white matter tract integrity across the adult lifespan and its relation to cortical thinning, PloS one 11 (2016) e0156770.

[89] I. O. Jelescu, M. D. Budde, Design and validation of diffusion mri models of white matter, Frontiers in physics 5 (2017) 61.

[90] D. S. Novikov, V. G. Kiselev, S. N. Jespersen, On modeling, Magnetic resonance in medicine 79 (2018) 3172-3193.

[91] S. J. Ritchie, S. R. Cox, X. Shen, M. V. Lombardo, L. M. Reus, C. Alloza, M. A. Harris, H. L. Alderson, S. Hunter, E. Neilson, et al., Sex differences in the adult human brain: evidence from 5216 uk biobank participants, Cerebral Cortex 28 (2018) 2959-2975.

[92] A. N. Kaczkurkin, A. Raznahan, T. D. Satterthwaite, Sex differences in the developing brain: insights from multimodal neuroimaging, Neuropsychopharmacology 44 (2019) 71.

[93] N. M. Armstrong, Y. An, L. Beason-Held, J. Doshi, G. Erus, L. Ferrucci, C. Davatzikos, S. M. Resnick, Sex differences in brain aging and predictors of neurodegeneration in cognitively healthy older adults, Neurobiology of aging 81 (2019) 146-156.

[94] D. Scheinost, E. S. Finn, F. Tokoglu, X. Shen, X. Papademetris, M. Hampson, R. T. Constable, Sex differences in normal age trajectories of functional brain networks, Human brain mapping 36 (2015) 1524-1535.

[95] E. Biskup, F.-C. Quevenco, M. T. Ferretti, A. Santuccione-Chadha, Sex differences in brain metabolic activity: Beyond the concept of brain age, Proceedings of the National Academy of Sciences 116 (2019) 10630-10631.

[96] D. Cirillo, S. Catuara-Solarz, C. Morey, E. Guney, L. Subirats, S. Mellino, A. Gigante, A. Valencia, M. J. Rementeria, A. S. Chadha, et al., Sex and gender differences and biases in artificial intelligence for biomedicine and healthcare, NPJ digital medicine 3 (2020) 1-11.

[97] F. Alfaro-Almagro, M. Jenkinson, N. K. Bangerter, J. L. Andersson, L. Griffanti, G. Douaud, S. N. Sotiropoulos, S. Jbabdi, M. Hernandez-Fernandez, E. Vallee, et al., Image processing and quality control for the first 10,000 brain imaging datasets from uk biobank, Neuroimage 166 (2018) 400-424.

[98] K. L. Miller, F. Alfaro-Almagro, N. K. Bangerter, D. L. Thomas, E. Yacoub, J. Xu, A. J. Bartsch, S. Jbabdi, S. N. Sotiropoulos, J. L. Andersson, et al., Multimodal population brain imaging in the uk biobank prospective epidemiological study, Nature neuroscience 19 (2016) 1523.

[99] I. I. Maximov, D. Alnaes, L. T. Westlye, Towards an optimised processing pipeline for diffusion magnetic resonance imaging data: Effects of artefact corrections on diffusion metrics and their age associations in UK biobank, Human Brain Mapping 40 (2019) 4146-4162. 
[100] S. M. Smith, M. Jenkinson, H. Johansen-Berg, D. Rueckert, T. E. Nichols, C. E. Mackay, K. E. Watkins, O. Ciccarelli, M. Z. Cader, P. M. Matthews, T. E. Behrens, Tract-based spatial statistics: Voxelwise analysis of multi-subject diffusion data, NeuroImage 31 (2006) 1487-1505.

[101] S. Mori, S. Wakana, P. C. Van Zijl, L. Nagae-Poetscher, MRI atlas of human white matter, Elsevier, 2005.

[102] I. I. Maximov, D. van Der Meer, A.-M. G. de Lange, T. Kaufmann, A. Shadrin, O. Frei, T. Wolfers, L. T. Westlye, Fast quality control method for derived diffusion metrics (YTTRIUM) in big data analysis: UK biobank 18,608 example, Human brain mapping 42 (2021) $3141-3155$.

[103] T. Chen, C. Guestrin, Xgboost: A scalable tree boosting system, in: Proceedings of the 22nd acm sigkdd international conference on knowledge discovery and data mining, 2016, pp. 785-794.

[104] H. Liang, F. Zhang, X. Niu, Investigating systematic bias in brain age estimation with application to post-traumatic stress disorders, Human brain mapping (2019).

[105] H. Li, T. D. Satterthwaite, Y. Fan, Brain age prediction based on resting-state functional connectivity patterns using convolutional neural networks, in: 2018 IEEE 15th International Symposium on Biomedical Imaging (ISBI 2018), IEEE, 2018, pp. 101-104.

[106] A.-M. G. de Lange, J. H. Cole, Commentary: Correction procedures in brain-age prediction, NeuroImage: Clinical 26 (2020).

[107] T. T. Le, R. T. Kuplicki, B. A. McKinney, H.-w. Yeh, W. K. Thompson, M. P. Paulus, T. . Investigators, et al., A nonlinear simulation framework supports adjusting for age when analyzing brainage, Frontiers in aging neuroscience 10 (2018).

[108] C. Bycroft, C. Freeman, D. Petkova, G. Band, L. T. Elliott, K. Sharp, A. Motyer, D. Vukcevic, O. Delaneau, J. O'Connell, et al., The uk biobank resource with deep phenotyping and genomic data, Nature 562 (2018) 203.

[109] D. M. Lyall, J. Ward, S. J. Ritchie, G. Davies, B. Cullen, C. Celis, M. E. Bailey, J. Anderson, J. Evans, D. F. Mckay, et al., Alzheimer disease genetic risk factor apoe e4 and cognitive abilities in 111,739 uk biobank participants, Age and ageing 45 (2016) 511-517.

[110] D. M. Lyall, S. R. Cox, L. M. Lyall, C. Celis-Morales, B. Cullen, D. F. Mackay, J. Ward, R. J. Strawbridge, A. M. McIntosh, N. Sattar, et al., Association between apoe e4 and white matter hyperintensity volume, but not total brain volume or white matter integrity, Brain imaging and behavior (2019) 1-9.

[111] N. M. Wisdom, J. L. Callahan, K. A. Hawkins, The effects of apolipoprotein e on non-impaired cognitive functioning: a meta-analysis, Neurobiology of aging 32 (2011) 63-74.

[112] P. Elliott, T. C. Peakman, The uk biobank sample handling and storage protocol for the collection, processing and archiving of human blood and urine, International journal of epidemiology 37 (2008) 234-244. 
[113] K. B. Schelbert, Comorbidities of obesity, Primary Care: Clinics in Office Practice 36 (2009) $271-285$.

[114] J. Jarolimova, J. Tagoni, T. A. Stern, Obesity: its epidemiology, comorbidities, and management, The primary care companion for CNS disorders 15 (2013).

[115] C. Ranasinghe, P. Gamage, P. Katulanda, N. Andraweera, S. Thilakarathne, P. Tharanga, Relationship between body mass index (bmi) and body fat percentage, estimated by bioelectrical impedance, in a group of sri lankan adults: a cross sectional study, BMC Public Health 13 (2013) 1-8.

[116] W. Chen, H. Xu-Hong, M.-L. Zhang, B. Yu-Qian, Z. Yu-Hua, W.-H. Zhong, K.-S. Xiang, J. Wei-Ping, Comparison of body mass index with body fat percentage in the evaluation of obesity in chinese, Biomedical and environmental sciences 23 (2010) 173-179.

[117] J. Wiltink, M. Michal, P. S. Wild, I. Zwiener, M. Blettner, T. Münzel, A. Schulz, Y. Kirschner, M. E. Beutel, Associations between depression and different measures of obesity (bmi, wc, whtr, whr), BMC psychiatry 13 (2013) 1-7.

[118] P. K. Myint, C. S. Kwok, R. N. Luben, N. J. Wareham, K.-T. Khaw, Body fat percentage, body mass index and waist-to-hip ratio as predictors of mortality and cardiovascular disease, Heart 100 (2014) 1613-1619.

[119] S. Wasti, S. Robinson, Y. Akhtar, S. Khan, N. Badaruddin, Characteristics of menopause in three socioeconomic urban groups in karachi, pakistan, Maturitas 16 (1993) 61-69.

[120] T. Gordon, W. B. KAnNEL, M. C. HJORTLAND, P. M. McNAMARA, Menopause and coronary heart disease: the framingham study, Annals of internal medicine 89 (1978) 157161.

[121] S. D. Harlow, M. Gass, J. E. Hall, R. Lobo, P. Maki, R. W. Rebar, S. Sherman, P. M. Sluss, T. J. de Villiers, S. . C. Group, Executive summary of the stages of reproductive aging workshop +10 : addressing the unfinished agenda of staging reproductive aging, The Journal of Clinical Endocrinology \& Metabolism 97 (2012) 1159-1168.

[122] R. D. Brinton, J. Yao, F. Yin, W. J. Mack, E. Cadenas, Perimenopause as a neurological transition state, Nature reviews endocrinology 11 (2015) 393-405.

[123] W. Rocca, J. Bower, D. Maraganore, J. Ahlskog, B. Grossardt, M. De Andrade, L. r. Melton, Increased risk of cognitive impairment or dementia in women who underwent oophorectomy before menopause, Neurology 69 (2007) 1074-1083.

[124] Y. Benjamini, Y. Hochberg, Controlling the false discovery rate: a practical and powerful approach to multiple testing, Journal of the Royal statistical society: series B (Methodological) 57 (1995) 289-300.

[125] E. Chang, M. Varghese, K. Singer, Gender and sex differences in adipose tissue, Current diabetes reports 18 (2018) 1-10.

[126] M. A. Bredella, Sex differences in body composition, Sex and gender factors affecting metabolic homeostasis, diabetes and obesity (2017) 9-27. 
[127] P. Gilsanz, C. Lee, M. M. Corrada, C. H. Kawas, C. P. Quesenberry, R. A. Whitmer, Reproductive period and risk of dementia in a diverse cohort of health care members, Neurology 92 (2019) e2005-e2014.

[128] L. Mosconi, A. Rahman, I. Diaz, X. Wu, O. Scheyer, H. W. Hristov, S. Vallabhajosula, R. S. Isaacson, M. J. de Leon, R. D. Brinton, Increased alzheimer's risk during the menopause transition: A 3-year longitudinal brain imaging study, PloS one 13 (2018) e0207885.

[129] J. Najar, S. Östling, M. Waern, A. Zettergren, S. Kern, H. Wetterberg, T. Hällström, I. Skoog, Reproductive period and dementia: A 44-year longitudinal population study of swedish women, Alzheimer's \& Dementia 16 (2020) 1153-1163.

[130] M. I. Geerlings, A. Ruitenberg, J. C. Witteman, J. C. van Swieten, A. Hofman, C. M. van Duijn, M. M. Breteler, L. J. Launer, Reproductive period and risk of dementia in postmenopausal women, Jama 285 (2001) 1475-1481.

[131] A.-M. G. de Lange, C. Barth, T. Kaufmann, I. I. Maximov, D. van der Meer, I. Agartz, L. T. Westlye, Women's brain aging: Effects of sex-hormone exposure, pregnancies, and genetic risk for alzheimer's disease, Human brain mapping 41 (2020) 5141-5150.

[132] C. Barth, A.-M. G. de Lange, Towards an understanding of women's brain aging: the immunology of pregnancy and menopause, Frontiers in Neuroendocrinology (2020) 100850.

[133] C. R. Jack Jr, D. S. Knopman, W. J. Jagust, L. M. Shaw, P. S. Aisen, M. W. Weiner, R. C. Petersen, J. Q. Trojanowski, Hypothetical model of dynamic biomarkers of the alzheimer's pathological cascade, The Lancet Neurology 9 (2010) 119-128.

[134] R. D. Brinton, Investigative models for determining hormone therapy-induced outcomes in brain: evidence in support of a healthy cell bias of estrogen action, Annals of the New York Academy of Sciences 1052 (2005) 57-74.

[135] A. Rahman, E. Schelbaum, K. Hoffman, I. Diaz, H. Hristov, R. Andrews, S. Jett, H. Jackson, A. Lee, H. Sarva, et al., Sex-driven modifiers of alzheimer risk: a multimodality brain imaging study, Neurology 95 (2020) e166-e178.

[136] E. Schelbaum, L. Loughlin, S. Jett, C. Zang, G. Jang, N. Malviya, H. Hristov, S. Pahlajani, R. Isaacson, J. P. Dyke, et al., Association of reproductive history with brain mri biomarkers of dementia risk in midlife, Neurology (2021).

[137] M. Fox, C. Berzuini, L. A. Knapp, Cumulative estrogen exposure, number of menstrual cycles, and alzheimer's risk in a cohort of british women, Psychoneuroendocrinology 38 (2013) 2973-2982.

[138] A. Mishra, R. D. Brinton, Inflammation: bridging age, menopause and apoec4 genotype to alzheimer's disease, Frontiers in aging neuroscience 10 (2018).

[139] O. Scheyer, A. Rahman, H. Hristov, C. Berkowitz, R. Isaacson, R. D. Brinton, L. Mosconi, Female sex and alzheimer's risk: the menopause connection, The journal of prevention of Alzheimer's disease 5 (2018) 225-230. 
[140] Y. Taki, S. Kinomura, K. Sato, K. Inoue, R. Goto, K. Okada, S. Uchida, R. Kawashima, H. Fukuda, Relationship between body mass index and gray matter volume in 1,428 healthy individuals, Obesity 16 (2008) 119-124.

[141] I. A. Dekkers, P. R. Jansen, H. J. Lamb, Obesity, brain volume, and white matter microstructure at mri: a cross-sectional uk biobank study, Radiology 291 (2019) 763-771.

[142] M. R. Meyer, D. J. Clegg, E. R. Prossnitz, M. Barton, Obesity, insulin resistance and diabetes: sex differences and role of oestrogen receptors, Acta Physiologica 203 (2011) 259-269.

[143] K. Blouin, C. Richard, G. Brochu, F.-S. Hould, S. Lebel, S. Marceau, S. Biron, A. Tchernof, et al., Androgen inactivation and steroid-converting enzyme expression in abdominal adipose tissue in men, Journal of Endocrinology 191 (2006) 637-649.

[144] D. E. Vosberg, N. Parker, J. Shin, Z. Pausova, T. Paus, The genetics of testosterone contributes to "femaleness/maleness" of cardiometabolic traits and type 2 diabetes, International Journal of Obesity (2021) 1-3.

[145] L. S. Robison, O. J. Gannon, A. E. Salinero, K. L. Zuloaga, Contributions of sex to cerebrovascular function and pathology, Brain research 1710 (2019) 43-60.

[146] O. Gannon, L. Robison, A. Custozzo, K. Zuloaga, Sex differences in risk factors for vascular contributions to cognitive impairment \& dementia, Neurochemistry international 127 (2019) $38-55$.

[147] D. M. Lyall, S. R. Cox, L. M. Lyall, C. Celis-Morales, B. Cullen, D. F. Mackay, J. Ward, R. J. Strawbridge, A. M. McIntosh, N. Sattar, et al., Association between apoe e4 and white matter hyperintensity volume, but not total brain volume or white matter integrity, Brain imaging and behavior 14 (2020) 1468-1476.

[148] K. E. Lawrence, L. Nabulsi, V. Santhalingam, Z. Abaryan, J. E. Villalon-Reina, T. M. Nir, I. B. Gari, A. H. Zhu, E. Haddad, A. M. Muir, et al., Age and sex effects on advanced white matter microstructure measures in 15,628 uk biobank participants, bioRxiv (2021) 2020-09.

[149] O. D. Leinhard, A. Johansson, J. Rydell, O. Smedby, F. Nystrom, P. Lundberg, M. Borga, Quantitative abdominal fat estimation using mri, in: 2008 19th International Conference on Pattern Recognition, IEEE, 2008, pp. 1-4.

[150] J. Linge, M. Borga, J. West, T. Tuthill, M. R. Miller, A. Dumitriu, E. L. Thomas, T. Romu, P. Tunón, J. D. Bell, et al., Body composition profiling in the uk biobank imaging study, Obesity 26 (2018) 1785-1795.

[151] T. P. Gurholt, T. Kaufmann, O. Frei, D. Alnæs, U. K. Haukvik, D. van der Meer, T. Moberget, K. S. O'Connell, O. D. Leinhard, J. Linge, et al., Population-based body-brain mapping links brain morphology with anthropometrics and body composition, Translational psychiatry 11 (2021) 1-12.

[152] J. Linge, B. Whitcher, M. Borga, O. Dahlqvist Leinhard, Sub-phenotyping metabolic disorders using body composition: an individualized, nonparametric approach utilizing large data sets, Obesity 27 (2019) 1190-1199. 
[153] E. Diehl-Wiesenecker, C. A. von Arnim, L. Dupuis, H.-P. Mueller, A. C. Ludolph, J. Kassubek, Adipose tissue distribution in patients with alzheimer's disease: a whole body mri case-control study, Journal of Alzheimer's Disease 48 (2015) 825-832.

[154] S. R. El Khoudary, K. J. Shields, I. Janssen, C. Hanley, M. J. Budoff, E. Barinas-Mitchell, S. A. Everson-Rose, L. H. Powell, K. A. Matthews, Cardiovascular fat, menopause, and sex hormones in women: the swan cardiovascular fat ancillary study, The Journal of Clinical Endocrinology \& Metabolism 100 (2015) 3304-3312.

[155] D. Szucs, J. P. Ioannidis, Sample size evolution in neuroimaging research: An evaluation of highly-cited studies (1990-2012) and of latest practices (2017-2018) in high-impact journals, NeuroImage 221 (2020) 117164.

[156] A. Fry, T. J. Littlejohns, C. Sudlow, N. Doherty, L. Adamska, T. Sprosen, R. Collins, N. E. Allen, Comparison of sociodemographic and health-related characteristics of uk biobank participants with those of the general population, American journal of epidemiology 186 (2017) 1026-1034.

[157] K. M. Keyes, D. Westreich, Uk biobank, big data, and the consequences of nonrepresentativeness, The Lancet 393 (2019) 1297.

[158] H.-T. Wang, J. Smallwood, J. Mourao-Miranda, C. H. Xia, T. D. Satterthwaite, D. S. Bassett, D. Bzdok, Finding the needle in a high-dimensional haystack: Canonical correlation analysis for neuroscientists, NeuroImage 216 (2020) 116745.

[159] A. Mulugeta, A. Lumsden, E. Hyppönen, Unlocking the causal link of metabolically different adiposity subtypes with brain volumes and the risks of dementia and stroke: A mendelian randomization study, Neurobiology of Aging 102 (2021) 161-169.

[160] R. M. Shansky, A. Z. Murphy, Considering sex as a biological variable will require a global shift in science culture, Nature neuroscience 24 (2021) 457-464.

[161] B. Ewelina, M. Julie, F. M. Teresa, Gender medicine: Towards a gender-specific treatment of neuropsychiatric disorders, in: Handbook of Clinical Neurology, volume 175, Elsevier, 2020, pp. $437-448$.

[162] J. A. Clayton, Applying the new sabv (sex as a biological variable) policy to research and clinical care, Physiology \& behavior 187 (2018) 2-5.

[163] L. R. Miller, C. Marks, J. B. Becker, P. D. Hurn, W.-J. Chen, T. Woodruff, M. M. McCarthy, F. Sohrabji, L. Schiebinger, C. L. Wetherington, et al., Considering sex as a biological variable in preclinical research, The FASEB Journal 31 (2017) 29-34.

[164] R. M. Shansky, C. S. Woolley, Considering sex as a biological variable will be valuable for neuroscience research, Journal of Neuroscience 36 (2016) 11817-11822.

[165] M. T. Ferretti, M. F. Iulita, E. Cavedo, P. A. Chiesa, A. S. Dimech, A. S. Chadha, F. Baracchi, H. Girouard, S. Misoch, E. Giacobini, et al., Sex differences in alzheimer disease - the gateway to precision medicine, Nature Reviews Neurology 14 (2018) 457-469.

[166] C. Taylor, L. Pritschet, S. Yu, E. G. Jacobs, Applying a women's health lens to the study of the aging brain, Frontiers in Human Neuroscience 13 (2019) 224. 
[167] E. G. Jacobs, J. M. Goldstein, The middle-aged brain: Biological sex and sex hormones shape memory circuitry, Current opinion in behavioral sciences 23 (2018) 84-91.

[168] M. T. Ferretti, A. Santuccione Chadha, The missing x factor in alzheimer disease, Nature Reviews Neurology (2021) 1-2.

[169] A. de Lange, E. G. Jacobs, L. A. Galea, The scientific body of knowledge: Whose body does it serve? a spotlight on women's brain health., Frontiers in Neuroendocrinology (2020) $100898-100898$. 